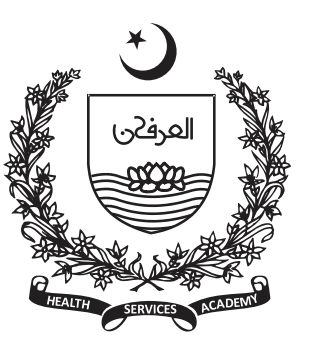

1 PhD, Assistant Professor, FG Degree Coll (M), Kharian Cantt.

2 PhD, Assistant Professor, FG Coll., Sialkot Cantt.

${ }^{3}$ MBBS, House Officer, PIMS, Islamabad.

4 8th Semester, BS Mechanical Engg., Intl Isl Uni Islamabad.

Corresponding author: Mujahid Hussain hmujahid64@yahoo.com

\title{
Coronavirus; Chemistry of Washing Hands with Soap for 20 Seconds
}

\author{
Mujahid Hussain¹, Imdad Hussain², Mahnoor³, Muhammad Gulsher
}

\section{Abstract}

The coronavirus also called 2019 novel coronavirus (2019-nCoV) or severe acute respiratory syndrome coronavirus 2 (SARS-2) is notorious for its pandemic corona virus disease 2019 (COVID-19). By 20 April 2020 (11.44 GMT), the pandemicity has inflicted more than 2.42 million people in the world resulting in more than 165,903 deaths (case fatality rate $=14.6 \%$ ). However, due credit goes to health care professionals for saving 635,761 lives i.e. $26.3 \%$ of the total affected population. On the other side, the economy of the countries has drastically been shattered in this scenario. According to an estimate, sole Pakistan will have to meet an economic loss of 1.3 trillion Pak rupees, provided the outbreak is controlled within short time span. Similarly, associated psychological disorders and social displeasure cannot be set aside.

\section{Introduction}

$\mathrm{I}$ $n$ the absence of effective vaccine and antiviral drug(s) against the deadly virus, the significance dogma shifts to preventive measures ranging from self-quarantine at home to social distancing at public places beside rapid diagnostics (4-6). The American centers for disease control and prevention (CDC) has issued a guideline for prevention from the virion with special emphasis on washing hands with bath soap on returning from public place or after blowing the nose, coughing or sneezing (5). Moreover, use of hand sanitizer (with at least $60 \%$ ethanol) is an alternate to the water wash on finding no hand washing facility or at the time of urgency.

However, one can only be benefitted from the disinfectants following internationally recommended protocols.

\section{Morphology of Corona virion}

The corona virion is a nanoparticle with a single stranded RNA which is covered by nucleocapsid protein (6). The envelope (E) and membrane (M) glycoproteins are embedded in the envelope - a lipid bilayer. The most distinguished component is proteinaceous spike which are attached with outer surface of the envelope. Presence of crownlike spikes on the virus gave it the name of coronavirus.

\section{Interviral clumping and attachment with hands}

Supramolecular chemistry, nanoscience and virology help in understanding the viral structure, their aggregation, and attachment/removal from the human hand (7). The chemical bonding can be seen at three stages i.e. self-assembly of individual particle, group assembly of many particles to make an aggregate/clump, and association of the aggregate with inanimate surface. During intracellular selfassembly of coronavirus, the molecules of the lipid bilayer remain loosely interlinked whereas weak covalent bonds develop among constituent compounds i.e. RNA, proteins and lipids. On the other side, strong hydrogen bonding (as in water) works 
among spikes of different viral particles in aggregate formation. The clumping increases stability (inactivity/inertness) of individual particles on dead skin cells of hand. At the end, aggregate's association with proteins and fatty acids in dead cells of the human hand is materialized by hydrogen and fat-like hydrophobic interactions. Moreover, the roughness of the hand reinforces the aggregate - hand interactions. The virion stays stable so long it is inactive; hence, hands are just sticky trap of the virus. However, the stability may decrease with exposure to moisture (softening), sunlight (UV radiations), or heat (molecular collisions). Similarly, risk of infection increases when contaminated hand touches eyes or nasal mucus membrane, unintentionally. Once pathogen get entry in the body, immune system activates as third defense line to neutralize it; otherwise, there is high chance of clinical symptoms of COVID-19.

\section{Mechanism of soap action in 20 seconds}

The soap liberates amphiphilic pin-shaped molecules, each with hydrophilic nonfatty head and hydrophobic fatty tail in a solvent (8). In water, the molecules approach to target fatty substance/micro structure and make a micelle. In a micelle, the tails compactly orient on the periphery of the target radiating heads outside. The heads develop hydrogen bonds with water molecules. So, micelle looks like a circle of radiating rays from a light source. Water molecules exert pull on the target via micelle to tear it apart before lifting. In case of coronavirus, the same principal works to dissociate the viral aggregate from the dead cells of hand, and liberation of individual viral particles from the aggregate by attacking on inter spike associations. Actual disintegration of the virion occurs when micelle operates on the weak linkages among viral lipid bilayer. The chain mechanism does not stop here but continues as micelle also picks the fragments of the destructed virion to ensure their removal along with the flooded clean water. Moreover, the overall mechanism accelerates on sufficient rubbing and scrubbing the hands with soapy lather. Strict adherence to the standard hand washing procedure (of 20 seconds) with soap warrants elimination of maximum population of destructed, damaged and intact pathogenic coronavirus. The prescribed method (against coronavirus) of hand washing with soap by the CDC is quite comprehensive in terms of outcomes (5). Wetting of hands with clean running water is followed by rubbing the soap on palms to produce lather. The lather is shifted to back of the hands, fingers and toes, and cuffs. The actual phase is scrubbing of all these areas for at least 20 seconds (9), an appropriate time period for efficient soap action for removal of all the sticky virions. Moreover, friction-producing lengthy rubbing and scrubbing support in eradication of the particles from every crevice and crack of the hands before water flooding and drying with cloth towel or hand drying device.

\section{Conclusion}

- There is intense need of hygiene literacy followed by attitude and practice of the hand wash in the community especially underprivileged segments e.g. prisoners, slum dwellers, and clean water-deprived people.

- The social, electronic and paper media should launch an integrated awareness campaign highlighting adverse outcomes of not cleaning the hands as per $\mathrm{CDC}$ recommendations.

\section{References}

1. COVID-19 coronavirus pandemic. https:/ / www.worldometers.info/coronavirus/

Accessed 20 April 2020.

2. Haider, M. Coronavirus: Pakistan may face initial economic loss of Rs1.3tr. The News; 20 March 2020. https://www.thenews.com.pk/print/631789coronavirus-pakistan-may-face-initial-economic-lossof-rs1-3tr . Accessed 15 April 2020.

3. Jun Zhang, Weili Wu, Xin Zhao, Wei Zhang, Recommended psychological crisis intervention response to the 2019 novel coronavirus pneumonia outbreak in China: a model of West China Hospital. Precis Clin Med. 2020;3(1):3-8.

4. Pang J, Wang MX, Ang IY, Tan SH, Lewis RF, Chen JI, et al. Potential rapid diagnostics, vaccine and therapeutics for 2019 novel coronavirus (2019-nCoV): a systematic review. J Clin Med. 2020; doi:10.3390jcm9030630

5. Centers for disease control and prevention (CDC). Coronavirus disease 2019 (COVID-19); How to protect yourself and others. https://www.cdc.gov/coronavirus/2019-

ncov/prevent-getting-sick/ prevention.html. Accessed 15 April 2020.

6. Shereen M A, Khan S, Kazmi A, Bashir N, Siddique R. COVID-19 infection: Origin, transmission, and characteristics of human coronaviruses. J Adv Res. 2020;24:91-98. 


\section{Commentary}

7. Thordarson P. Why does soap work so well on SARSCoV-2? University of South Wales, Australia; 9 Mar 2020. https://virologydownunder.com/why-doessoap-work-so-well-on-sars-cov-2/ . Accessed 15 April 2020.

8. Corum J, Jaber F. Why soap works. The New York Times; $13 \quad$ March 2020. https://www.nytimes.com/2020/03/13/health/soap- coronavirus-handwashing-germs.html . Accessed 15 April 2020.

9. Todd EC, Michaels BS, Smith D, Greig JD, Bartleson CA. Outbreaks where food workers have been implicated in the spread of foodborne disease. Part 9. Washing and drying of hands to reduce microbial contamination. J Food Prot. 2010;73(10):1937-55. 